\title{
TRUST ĀND GOVERNANCE: UNTANGLING A TANGLED WEB
}

\author{
PHANISH PURANAM \\ BART S. VANNESTE \\ London Business School
}

\begin{abstract}
Using a simple but general formalization, we state the conditions under which one might expect $\alpha$ negative or positive relationship between preexisting trust and governance complexity, and whether crowding out or complementarity arguments are necessary for such outcomes. Our analysis provides a platform for simple but rigorous analysis of other possible relationships between trust and governance and also suggests that the debate about the relationship between governance and trust could be fruitfully redirected through greater attention to the analytical structure of the arguments.
\end{abstract}

In recent years several scholars have explicitly addressed the question of whether trust and governance mechanisms like contracts and ownership relate to each other as substitutes or as complements (Corts \& Singh, 2004; Gulati \& Nickerson, in press; Lazzarini, Miller, \& Zenger, 2004; Luo, 2002; Poppo \& Zenger, 2002; Ryall \& Sampson, in press; Woolthuis, Hillebrand, \& Nooteboom, 2005). While individually insightful, these studies cumulatively also suggest a bewildering array of possible relationships between trust and governance, at least some of which appear incompatible with one another.

Trust- the expectation that an exchange partner will not behave opportunistically, even when such behavior cannot be detected by the victim-is a powerful alternative to formal governance mechanisms that attempt to align incentives and control opportunism through monitoring and sanctions (Bradach \& Eccles, 1989; Mayer, Davis, \& Schoorman, 1995). By limiting (concerns about) opportunism, both trust and governance ultimately allow exchange relationships to be formed, as well as effective adaptation to the changes that are inevitable in any

We thank Eva Ascarza, Sourav Bhattacharya, Pascale Crama, Rahul Kapoor, Kyle Mayer, Madan Pillutla, Markus Reitzig, and seminar participants at the London Business School. We also acknowledge Michael Ryall and three anonymous reviewers for helpful comments. Puranam acknowledges funding from the Mack Center for Technological Innovation at the Wharton School. Vanneste gratefully acknowledges a Marie Curie Fellowship of the European Union. The views presented in this article are not necessarily the views of the European Commission. long-term exchange relationship (Gulati, Lawrence, \& Puranam, 2005; Williamson, 1991). Since governance mechanisms are not free, trust could reduce reliance on formal governance mechanisms (Bradach \& Eccles, 1989; Granovetter, 1985; Macaulay, 1963; Macneil, 1978; Ring \& Van de Ven, 1992). Indeed, some have argued for a stronger form of substitution between trust and governance-reliance on complex governance mechanisms may actively hinder the development of or destroy trust in exchange relationships (Ghoshal \& Moran, 1996; Macaulay, 1963; Malhotra \& Murnighan, 2002).

Yet, as Poppo and Zenger (2002) have shown in an insightful analysis, trust may also leverage the effects of governance on exchange performance so that it encourages rather than discourages the use of formal governance mechanisms. Developing this line of reasoning further, Gulati and Nickerson (in press) have argued that trust may enhance exchange performance in combination with formal governance mechanisms (such as ownership), but at the same time it may make such mechanisms less necessary. Perhaps reflecting this diversity of arguments about the relationships between trust and governance, the empirical evidence has been mixed; some scholars report a negative relationship between trust (or its proxies, such as repeated interactionsalthough see Vanneste \& Puranam [in press] for the problems with this approach) and governance complexity (Banerjee \& Duflo, 2000; Corts \& Singh, 2004; Crocker \& Reynolds, 1993; Gulati, 1995; Kalnins \& Mayer, 2004; Parkhe, 1993), while others report a positive relationship (Luo, 2002;

Copyright of the Academy of Management, all rights reserved. Contents may not be copied, emailed, posted to a listserv, or otherwise transmitted without the copyrigh holder's express written permission. Users may print, download, or email articles for individual use only. 
Mayer \& Argyres, 2004; Poppo \& Zenger, 2002; Ryall \& Sampson, in press; Zaheer \& Venkatraman, 1995), and some find no relationship at all (Mellewigt, Madhok, \& Webel, 2007).

In this paper we attempt to reconcile these diverse arguments about the relationships between trust and governance as special cases of a more general framework. ${ }^{1}$ The apparent dichotomy implied by the "complements-substitutes" terminology fails to capture several different kinds of relationships between trust and governance that may, in fact, coexist. We use a simple but general formalization to model three different kinds of relationships between trust and governance that play out at different points in time (see Figure 1). These are (1) the relationship between ex ante levels of trust and the choice of governance mechanisms (Gulati, 1995); (2) complementarity - the leveraging effect of $\alpha$ given level of trust on the relationship between governance and exchange performance (Poppo \& Zenger, 2002); and (3) crowding out-the influence of governance mechanisms on suppressing trust (Malhotra \& Murnighan, 2002). While the last two are ex post effects that arise after a governance form is in place, they inevitably shape the relationship between ex ante trust and the choice of governance, if such choices are made with foresight (Williamson, 1985, 1991). The formalization we employ makes it possible to study these linkages between ex post effects and ex ante choices explicitly.

We begin with the premise that trust and governance both offer benefits similar to exchange relationships (Das \& Teng, 1998; Gulati, 1995; Poppo \& Zenger, 2002; Zaheer \& Venkatraman, 1995). Since concerns about opportunism can pre-

\footnotetext{
${ }^{1}$ For brevity, we use "governance" to indicate "formal governance" throughout the paper and treat it as distinct from trust.
}

vent the formation of an exchange relationship, trust (which implies the absence of such concerns) and governance (which alleviates them) both allow a basis for exchange. Further, given the limited rationality of individuals, unexpected changes in exchange conditions are inevitable; complex governance and trust both can allow exchange partners to surmount the coordination challenges and incentive conflicts created by change (Gulati et al., 2005; Williamson, 1991). We formulate a decision problem in which a manager chooses the appropriate level of governance complexity in order to exploit its benefits, taking into account the costs of designing and implementing governance, as well as the preexisting level of trust between exchange partners and possible complementarity and crowding out effects between trust and governance.

Formally analyzing these relationships jointly gives rise to some surprising insights not easily accessible with verbal theorizing alone. The basic one is the sensitivity of predictions about relationships between trust and governance to assumptions about the goal of the decision maker. Predictions diverge significantly depending on whether the manager's task is fromed as one of selecting a level of governance complexity to match the need for safeguards and adaptation implied by transaction characteristics (Gulati, 1995; Parkhe, 1993; Zaheer \& Venkatraman, 1995), or whether the task is framed as a problem of maximizing exchange performance given transaction characteristics (Corts \& Singh, 2004; Kalnins \& Mayer, 2004; Saussier, 2000; Williamson, 1991). Researchers typically have not articulated the nature of the underlying decision problem that they implicitly assume when discussing trust and governance choices, and this may account for diverging opinions about the relationship between the two. We go on to obtain several interesting results about when effects like complementarity or crowding

FIGURE 1

Time Line: Governance Choice, Trust, and Benefits

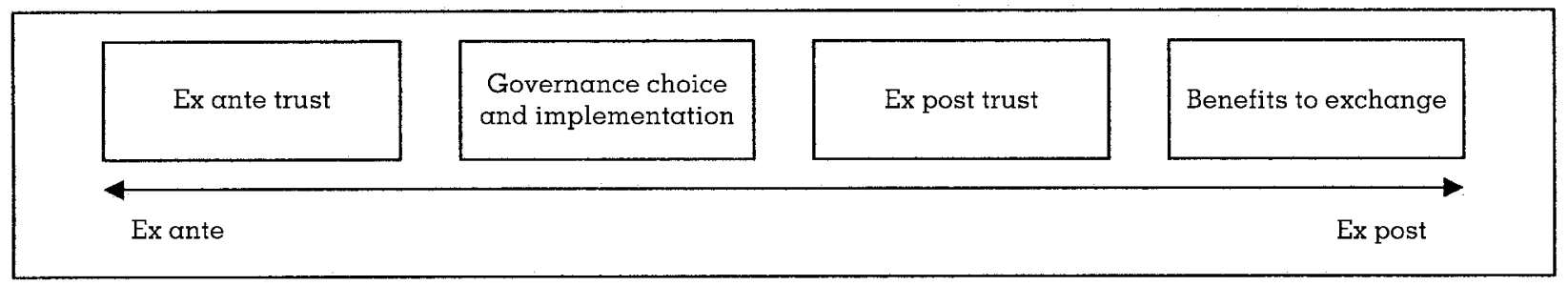


out are either necessary or unnecessary to predict a particular sign for the relationship between trust and governance.

Our analysis provides a rigorous, general, and integrated approach to studying the complex relationships between trust and governance, and it allows us to reconcile apparently incompatible arguments in prior literature. Our analysis offers $\alpha$ more nuanced yet clearer view of the relationship between trust and governance than is afforded by a simple complements-substitutes dichotomy. More generally, the paper demonstrates the advantages of even fairly simple formalizations in adding insights beyond those easily obtainable from verbal theorizing alone.

\section{GOVERNANCE, TRUST, AND EXCHANGE}

Given bounded rationality and self-interested or opportunistic behavior, economic exchange can be plagued by failures of cooperation and coordination, especially in situations of bilateral dependence between exchange partners (Gulati et al., 2005; Williamson, 1991). Transaction cost economics has explored in depth how investments in transaction-specific assets create holdup situations, which opportunistic actors may exploit (Klein, Crawford, \& Alchion, 1978; Williamson, 1985). The inherent challenges for economic transactions appear even more severe once we take into account the dynamic and uncertain environment in which they often take place. Indeed, Hayek argued that "the economic problem of society is mainly one of rapid adaptation to changes in the particular circumstances of time and place" (1945: 524). In changing circumstances exchange partners not only have to account for hazards that were foreseen but also have to adapt to conditions that were unforeseen at the initiation of the transaction (Gulati et al., 2005; Williamson, 1991).

An extensive body of work, including the transaction cost perspective, has helped to develop the view of formal governance mechanisms (such as firms and complex contracts) as providing the necessary safeguards and adaptation mechanisms that can protect economic exchange from the consequences of bounded rationality and opportunism (Coase, 1937; Williamson, 1975). More recently, scholars drawing from the sociological tradition have shifted the focus to informal governance in the form of trust, since trust can provide benefits similar to those of formal governance in terms of controlling opportunism and facilitating adaptation (Bradach \& Eccles, 1989; Granovetter, 1985; Gulati, 1995; Macaulay, 1963; Macneil, 1978; Uzzi, 1997).

In order to model how trust and governance, individually and jointly, enable exchange, we conceive of a "production function" in which trust and governance complexity are the key inputs, with interactions between them defined in terms of the crowding out and complementarity effects. The outputs are the benefits to exchange deriving from trust and governance-in terms of safeguards and the capacity for adapting to changing circumstances. ${ }^{2}$ We now discuss in detail these benefits and costs. See Figure 2 for an overview.

\section{The Benefits and Costs of Governance}

Governance mechanisms differ in their ability to mitigate incentive conflict and to enable coordinated action, based on their complexity. Distinguishing between basic types of governance modes, Williamson (1975) argued that hierarchies differ from markets in that the former feature administrative controls, such as authority, rules, and procedures. These instruments enable coordinated actions even in situations of high interdependence and complexity (March \& Simon, 1958; Thompson, 1967). Hierarchies are also characterized by suppressed incentive intensity and superior monitoring mechanisms, which mitigate the effects of conflicting incentives; opportunism is therefore less likely to be a hindrance. Williamson (1991) further argued that hybrid arrangements (e.g., alliances and joint ventures), which combine some aspects of market relationships (such as prices) as well as hierarchical structures (such as continuity of association, rules, and authority), lie intermediate between markets and hierarchies. This ordering of markets, hybrids, and hierorchies also holds when we consider their "adaptive capacity"their capacity to adapt to changes in the exchange setting that were unforeseen at the time

\footnotetext{
${ }^{2}$ While such benefits may also be thought of in terms of the avoidance of costs (such as those arising from holdup, bargaining, and coordination failure), we follow the practice of treating them as benefits in order to distinguish them from the costs incurred in setting up and implementing governance structures (Crocker \& Reynolds, 1993; Williamson, 1991).
} 
FIGURE 2

Theoretical Model of Governance, Trust, Benefits, and Costs

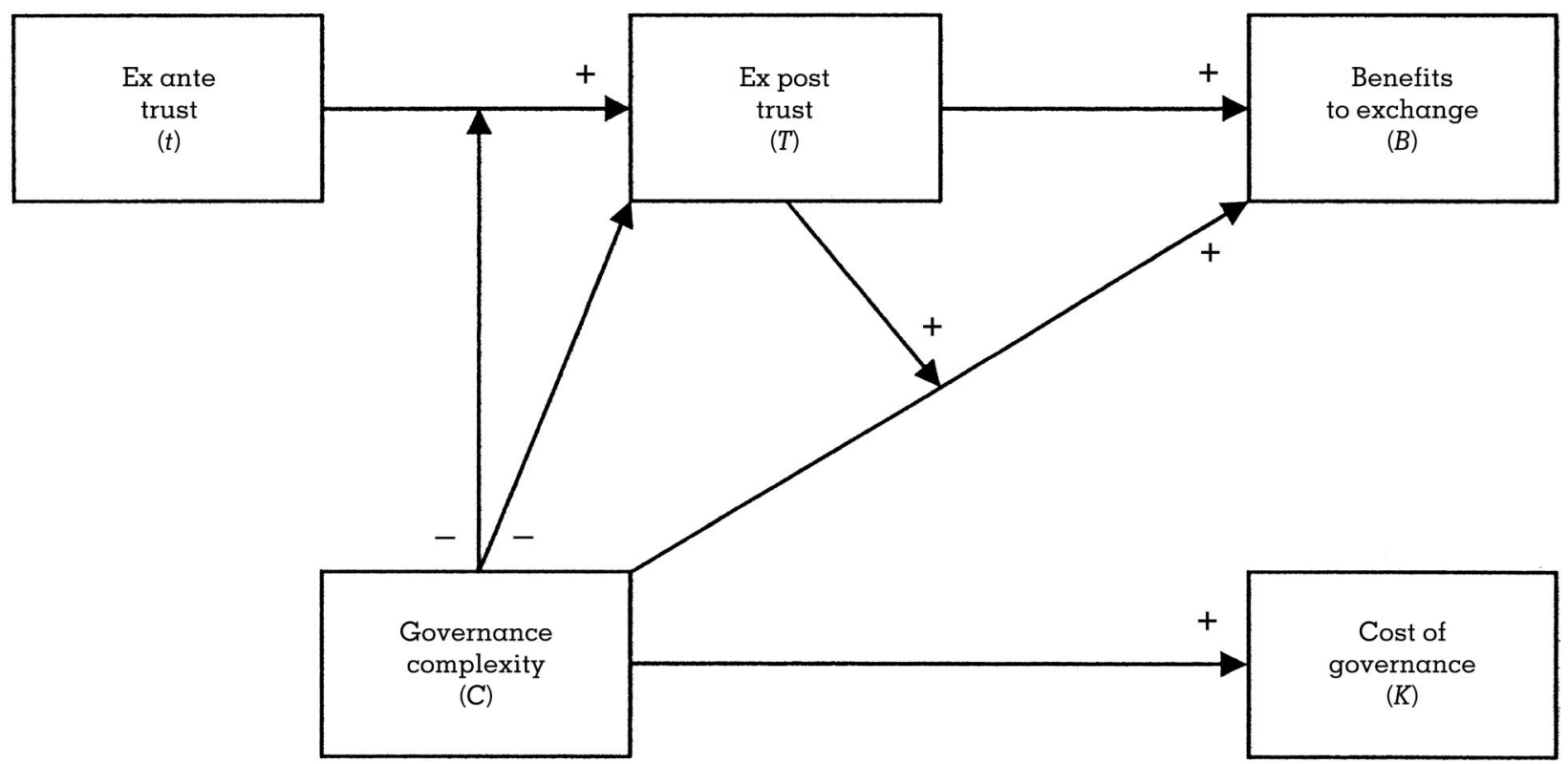

of governance initiation (Gulati et al., 2005; Williamson, 1991). ${ }^{3}$

While the preceding discussion focused on discrete governance modes and their ordering in terms of governance complexity (i.e., from markets to hierarchies), it is also possible to think of increasing complexity of governance within a governance mode, such as increasing contractual detail within contracting. Contractual detail is the extent to which clauses are specified in a contract (Mayer \& Argyres, 2004; Poppo \& Zenger, 2002; Ryall \& Sampson, in press). Analogous to the benefits of more complex governance modes, more detailed contracts are expected to provide better safeguards and more powerful mechanisms to achieve adaptation when necessary (Mayer \& Argyres, 2004;

\footnotetext{
${ }^{3}$ Following prior research (Gulati et al., 2005; Williamson, 1991), we focus on adaptation within the existing relationship, where parties to the exchange prefer continuation of the relationship over switching. Also note that the apparent inflexibility that characterizes hierarchy (in the form of rules and procedures) is not incompatible with adaptiveness. This is because constraints on individual action are compatible with joint adaptation. Put differently, adaptation problems in organizations often resemble coordination games, in which convergence to an equilibrium is preferable to nonconvergence (Camerer \& Knez, 1996). Rules, authority, procedures, and other such aspects of governance that appear to create inflexibility may guide such a convergence.
}

Parkhe, 1993). We articulate this assumption about the general relationship between the extent of governance complexity employed and the resulting benefits to exchange in terms of safeguards and adaptive capacity as follows.

Assumption 1: More governance complexity provides more benefits to an exchange relationship.

Setting up complex governance is costly. For instance, there are costs for adding contractual detail, such as the cost of negotiating, bargaining, drafting, and reaching agreement on the terms (Batenburg, Raub, \& Snijders, 2003; Macaulay, 1963). In the case of the choice between governance modes, designing and implementing more complex forms of governance, such as hybrids and hierarchies, are costlier than relying on market relationships (Williamson, 1985, 1991).

It is important to note that the costs of governance complexity-in terms of the costs of designing and implementing governance structures of a particular level of complexity-are incurred at the initiation of a governance format. The benefits in terms of rapid decision making, avoidance of costly renegotiation, rapid adaptation, and discouragement of attempts to behave opportunistically all arise during the period that 
the governance form is in force. For instance, in discussing governance complexity in the context of markets, hybrids, and hierarchies, Williamson (1991) distinguished between the irreducible setup costs of transactions and the potential adaptation benefits, which differ with governance complexity. The costs of governance complexity we model here refer to these irreducible setup costs. Thus, our second assumption relates the cost of governance to governance complexity.

Assumption 2: The greater the chosen level of governance complexity, the greater the cost of setting up such governance mechanisms will be.

\section{The Benefits of Trust}

Trust is " $\alpha$ type of expectation that alleviates the fear that one's exchange partner will act opportunistically" (Bradach \& Eccles, 1989: 104), even when it is not possible to monitor that partner (Mayer et al., 1995). Social psychologists have found that interpersonal trust develops out of prior interactions (Deutsch, 1973; Rempel, Holmes, \& Zanna, 1985), while organizational researchers have shown empirically that interfirm trust increases with repeated interactions (Anderson \& Weitz, 1989; Gulati \& Sytch, 2008; Parkhe, 1993). The information from prior interactions provides an opportunity to evaluate others' intentions and motives (Lindskold, 1978). This forms a basis for predictions about future behavior and inferences about trustworthiness (Anderson \& Weitz, 1989; Bhattacharya, Devinney, \& Pillutla, 1998; Buskens \& Raub, 2002; Kramer, 1999; Ring \& Von de Ven, 1992). ${ }^{4}$

If it is present in an exchange relationship, mutual trust decreases concerns about opportunism and allows exchanging partners to transact, even in the face of potential holdup

\footnotetext{
${ }^{4}$ The relational contracting literature suggests that besides a backward-looking aspect to trust, there is also a forward-looking component. Concerns for reputation (Klein \& Leffler, 1981) and the value of future interactions (Levin, 2003) may produce "trust" and trustworthy behavior, even in the absence of a shared history. Such forward-looking instances of cooperative behavior may be better captured under the label assurance (Williamson, 1993). Our own arguments about trust in this paper are most applicable to the backward-looking aspects of trust.
}

problems (Bradach \& Eccles, 1989; Kramer, 1999; Mayer et al., 1995). When unexpected changes arise, trust enables the parties to the exchange to proceed with implementing necessary changes, rather than worrying about opportunistic attempts to redistribute gains. Further, trust enhances the predictability of others' actions (Gulati, 1995). This enhanced predictability allows exchange partners to anticipate others' actions and to adjust their own accordingly when the need for such adjustment arises. Hence, trust also enhances adaptive capacity. We summarize this assumption about the benefits of ex post trust (i.e., trust present after the initiation of the transaction) to exchange as follows.

\begin{abstract}
Assumption 3: The greater the level of ex post trust in the exchange relationship, the greater the benefits to the relationship will be.
\end{abstract}

\section{Ex Post Relationships Between Governance and Trust}

While both trust and governance provide independent benefits to exchange, there are also important relationships between them that arise ex post: crowding out and complementarity effects. First, we discuss crowding out.

The use of complex governance mechanisms can crowd out trust in the sense that the level of trust in the relationship can be eroded when the partners rely on complex governance. Reliance on complex contracts or partial or complete equity ownership to manage an exchange relationship may signal a lack of trust to exchange partners (Macaulay, 1963). If one is not trusted, one trusts less, leading to a lower level of trust in the relationship (Enzle \& Anderson, 1993). Thus, the adoption of complex governance mechanisms may directly reduce the level of trust in the relationship (Frey, 1997; Ghoshal \& Moran, 1996). We call this the "direct crowding out effect."

\section{Assumption 4: Governance complexity reduces the level of ex post trust in the exchange relationship.}

The direct crowding out effect acts to suppress the level of trust in an exchange relationship after a governance structure has been selected, independent of the level of preexisting (ex ante) 
trust in the relationship. It is also possible to conceive of an additional indirect crowding out effect, where governance complexity serves to reduce the "buildup" or "carryover" of trust into an exchange relationship. Assume that there is an ex ante level of trust between potential exchange partners A and B. All else being equal, such ex ante trust will be positively associated with trust in the relationship once it is formed. This is because, absent the destruction of trust, ex ante trust will simply be "carried forward" into the relationship. Indeed, trust in the relationship may build up and increase relative to ex ante levels. In the course of the relationship, several opportunities will normally arise for the parties to engage in either trustworthy or opportunistic behavior. In the absence of formal governance, trustworthy behavior will be recognized as such, leading to an updated and increased level of trust in the relationship (Anderson \& Weitz, 1989; Porkhe, 1993; Ring \& Van de Ven, 1992).

However, now consider what happens when a complex governance structure is put in place to manage the exchange. The introduction of formal governance mechanisms can impede this process of trust formation, since trustworthy behavior is less likely to be attributed to the actor than to the governance mechanism (Malhotra \& Murnighan, 2002; Strickland, 1958). As such, governance complexity weakens the positive association between ex ante trust and trust in the relationship. We call this the "indirect crowding out effect."

Note that both direct and indirect crowding out serve to reduce trust in an exchange relationship, by either lowering the level of ex post trust in absolute terms (direct crowding out) or weakening the positive association between ex ante trust and ex post trust (indirect crowding out). We formalize the indirect crowding out effect as follows.

\section{Assumption 5: Governance complexity weakens the positive association be- tween ex ante trust and ex post trust in the exchange relationship.}

While governance mechanisms may crowd out trust relative to ex ante levels, at the same time it is possible that ex post trust and governance mechansisms will enhance each other's benefits, for any given level of each. This has been referred to as the complementarity effect of trust on gover- nance (Gulati \& Nickerson, in press; Poppo \& Zenger, 2002). To see how this complementarity effect can work, consider the following: all contractual clauses are ultimately imperfect in the sense that it is difficult to completely and unambiguously describe the relevant contingency and appropriate action. Without trust, these ambiguities might give rise to opportunistic attempts to hold up an exchange partner, which con frustrate efficient adaptation to changing circumstances. With trust, contractual clauses-however imperfect-will not raise concerns about opportunistic exploitation but, rather, will serve as a useful basis for efficient adaptation. In the presence of trust, therefore, an imperfect clause offers more protection than in the absence of trust, because trust can act as a "lubricant" that fills in the gaps (Arrow, 1974). Thus, the value to increasing governance complexity is greater in the presence of trust than in its absence. This is the classic analytical definition of complementarity (Milgrom \& Roberts, 1995), which is discussed by Poppo and Zenger (2002: 718) as a plausible relationship between trust and formal governance.

Conversely, trust can be more valuable when it coexists with complex contracts that help to prevent coordination failures. While trust resolves uncertainty about motives and helps to align incentives, successful exchange relationships also require protection from coordination failures $(\mathrm{Gu}-$ lati et al., 2005). The terms of the contract serve as an important coordination device by encoding common knowledge (Mayer \& Argyres, 2004). More complex contracts perform this function to a greater extent, thus providing greater coordination benefits. Similar arguments have been made about the possible complementarities between trust and governance modes such as markets and hierorchies (Gulati \& Nickerson, in press). We formalize these complementary joint effects of governance and trust as follows.

\section{Assumption 6: Governance complexity enhances the marginal benefits of ex post trust in exchange relationships, and vice versa.}

In the next section we develop a simple formal model that allows us to explore the joint implications of these assumptions for how a decision maker with foresight will make governance choices. In particular, we are interested in exploring how the ex post effects-complementarity and crowding out-influence the relation- 
ship between ex ante trust and the choice of governance complexity.

\section{MODEL}

Our model represents the problem that a decision maker (with foresight) faces in choosing an appropriate governance form for a transaction with another independent entity. ${ }^{5}$ The choice variable is $C \in[0, \rightarrow]$, which captures the complexity of governance relied on in managing the transaction. The symbols $t$ and $T$ denote ex ante and ex post levels of trust. We describe the model structure below, as well as how it captures the theoretical Assumptions 1 through 6 discussed earlier.

As we have noted, both trust and governance mechanisms are potentially valuable because of the benefits to exchange they confer, and they may act not only independently but also in combination (Assumptions 1, 3, and 6). We therefore specify a very general benefit function, which imposes the least possible structure on the functional form:

$$
\begin{aligned}
B=f(C)+ & g(T(C, t)) \\
& +\gamma f(C) g(T(C, t)), \text { where } C, t, T \geq 0 .
\end{aligned}
$$

There are potentially a large number of production functions that could be used to model the benefits to exchange generated by trust and governance, yet the formulation in (1) is particularly appropriate for several reasons. First, it is easy to characterize the independent and combined effects distinctly; the functions $f$ and $g$ model the independent benefits of governance and trust, respectively, when there is no interaction between them $(\gamma=0)$. The functions $f$ and $g$ are nonnegative, monotonically increasing in $C$ and $T$, respectively, $(f(C) \geq 0, \partial f / \partial C>0, g(T(C, t)) \geq$ $0, \partial g / \partial T>0)$. Further, we also impose the assumption that there are diminishing marginal returns to trust; the benefits of trust increase with trust levels but at a decreasing rate, $\partial^{2} g /$

\footnotetext{
${ }^{5}$ In line with previous research, we model the decision making of one party; we could view the results from the model as what would be most preferred by each individual partner-with what actually prevails in any given relationship also being affected by bargaining power.
}

$\partial T^{2}<0$. Thus, initial increases in trust are more valuable than later increases of the same magnitude. The diminishing marginal benefits assumption is common to many social phenomena, and it appears plausible for trust. It is also in line with prior research showing that the capacity of trust to facilitate adaptation diminishes for higher levels of trust (Uzzi, 1997). However, we later relax this assumption in our section on extensions. Note also that we make no specific assumption on the nature of the second derivative of $f$ at this point.

Second, the single parameter $\gamma \geq 0$ captures the nature of the interaction between the effects of governance and trust as stated in Assumption 6 . When $\gamma>0, f$ and $g$ are complements, in the sense that each enhances the marginal value of the other. Third, the magnitude of the interaction-complementarity-does not vary with the levels of the functions $f$ and g; it is always $\gamma$. All three properties aid interpretation and enhance the mapping between theory and the model. Thus, it becomes possible to examine situations where there are no interaction effects, or to separately evaluate the interactive and independent benefits of trust and governance quite easily. Furthermore, by changing a single parameter, one can study variations in the magnitude of the complementarity effects. Similar formulations have been widely used to model complementarities in team theory, as well as models of incentive structure (e.g., Cremer, 1993; Petersen, 1992; Siggelkow, 2002).

The cost of governance as specified in Assumption 2 is captured as follows:

$$
K=h(C) \geq 0 ; \frac{\partial h}{\partial C}>0 .
$$

Thus, the cost of governance, $h$, is a nonnegative, monotonically increasing function (we impose no restriction at this stage on the second derivative). All else being equal, the level of trust in the relationship (T) is a nonnegative quantity that increases in the levels of ex ante trust $(t)$. This implies

$$
T(C, t) \geq 0 ; \frac{\partial T}{\partial t}>0 .
$$

The direct crowding out effect is modeled as $\partial T / \partial C<0$, whereas the indirect crowding out effect is modeled as $\partial^{2} T / \partial C \partial t<0$, as specified in 
Assumptions 4 and 5. The absence of direct and indirect crowding out effects is treated as $\partial T /$ $\partial C=0$ and $\partial^{2} T / \partial C \partial t=0$, respectively. ${ }^{6}$

With these three elements in place, we are ready to consider the problem facing a decision maker who is seeking to choose an appropriate level of formal governance complexity for a transaction. We assume the actions unfold across three periods (see Figure 1). In the first period the decision maker chooses an optimal level of governance complexity for the relationship, given an ex ante trust level, and implements it, incurring relevant setup costs. In the second period, which commences after a governance structure has been implemented for the relationship, the crowding out effect operates and the level of ex post trust is determined. In the third period ex post trust and governance complexity jointly and in interaction generate benefits to the exchange in terms of smoothing adaptation and providing safeguards. The decision maker anticipates what is likely to happen in the second and third periods, and, therefore, his first period decision on governance complexity accounts for this. We frame this first period decision problem in two different ways, and, as we will show, the framing matters for the results.

First, we consider the "matching" approach, in which the decision maker forms some estimate of the "sufficient" level of adaptive capacity and safeguards necessary- $H$ (perhaps based on transactional characteristics)-and then chooses governance complexity sufficient to generate this level of benefit, keeping in mind the level of preexisting trust. This twostep process-an initial assessment of what is sufficient, followed by a choice of governance complexity that "fills in" what is still required after the effects of preexisting trust-defines the matching approach. The decision maker is thus satisficing (Cyert \& March, 1963; March \& Simon, 1958) by seeking a sufficient level of benefits $(H)$, rather than following a completely rational optimization approach seeking to equate the marginal benefits of governance complexity with its marginal costs. However, conditional on the choice of $H$, the matching approach does imply

\footnotetext{
${ }^{6}$ Note that, given our definition, it is analytically not feasible to have an indirect crowding out effect without a direct crowding out effect; it is, however, possible to have a direct crowding out effect without an indirect crowding out effect.
}

a rational approach to using formal governance to "fill in the gap" between $H$ and what preexisting trust can provide. This combination of bounded and more rational behavior is very similar in spirit to the standard transaction cost economics assumption that while decision makers are boundedly rational in their ability to foresee future contingencies, they are still rational in the sense that they con indulge in forsighted contracting (Williamson, 1996).

The matching logic underlies the arguments set forth by Macaulay (1963), who noted that noncontractual mechanisms such as norms and trust often provide sufficient protection on their own. More recently, the matching logic often has been (implicitly) invoked in the management literature on the interplay between trust and governance. For instance, Gulati (1995: 94) has argued that trust "reduces the imperative to use equity" as a protection mechanism in alliances. If trust sufficiently reduces the fear of opportunistic behavior, then there is no role for equity. Likewise, Parkhe (1993) and Zaheer and Venkatraman (1995) have suggested that trust reduces opportunism and therefore diminishes the need for contractual safeguards.

Our formalization of the matching approach tries to stay close to the two-step process described above. The satisficing behavior of the decision maker generates the constraint $B=H$, which we simply take as given and then calculate the optimal level of governance complexity conditional on this constraint. The optimization problem we solve is thus one of minimizing costs of governance $(K)$ subject to the constraint that the level of benefits generated by governance complexity and trust matches the level that the decision maker decides is sufficient $(H)$. Since the costs of governance are monotonically increasing in complexity, this is equivalent to solving for the lowest value of $C$ that satisfies $B=H$. We can think of this as optimization conditional on the constraint that $B=H .^{7}$

The second approach we take is to "maximize" the performance of the exchange relationship with respect to $C$. We assume that exchange performance can be conceptualized as

\footnotetext{
${ }^{7}$ Also see Camerer (2003: 474-475) for a discussion of the idea that optimality may indeed guide actions even though the problem formulation itself is faulty. Thus, the matching approach presumes optimal choice conditional on the (imperfect) representation of the optimization problem.
} 
benefits of governance and trust net the costs of governance. This approach is formally equivalent to maximizing $(B-K)$ and is therefore a "more" rational approach than the matching logic, which involves satisficing. With the maximizing formulation, transaction characteristics play an indirect role in influencing the marginal benefits of governance and trust; both are likely to have a greater impact on exchange performance when transactions are prone to hazards than when they are not. In this approach the optimization problem is one of finding the level of governance complexity that maximizes the difference between the benefits and costs of governance.

The maximizing approach most frequently appears in economics-and is most relevant in transaction cost economics (e.g., Williamson, 1975, 1985). For instance, Williamson (1991) has suggested that optimal governance complexity (in his case markets, hybrids, or hierarchies) is chosen such that the difference between benefits and costs is maximized, given a level of asset specificity. Similarly, when thinking of governance complexity as the level of contractual detail, one can distinguish between costs (e.g., the cost of negotiating and writing the contract) and benefits (e.g., protection against opportunistic behavior). Saussier (2000), Corts and Singh (2004), and Kalnins and Mayer (2004) have explicitly considered the case where agents maximize performance when deciding what contract to use, where performance equals benefits minus costs.

\section{RESULTS}

Our goal is to state which of the ex post effects (complementarity, direct or indirect crowding out) are necessary (or unnecessary) to predict a particular sign for the relationship between the extent of governance complexity and the level of ex ante trust in a relationship. We first state the results obtained through the matching approach and then turn to the maximizing approach (proofs of all propositions can be found in the Appendix).

Proposition 1: Under the matching approach, neither complementarity nor crowding out effects are necessary to obtain a negative relationship be- tween the level of ex ante trust and governance complexity.

The intuition for this result is fairly simple. If ex ante trust levels go up, then the benefits generated through trust go up; since the required level of benefits remains constant for a given set of transactional attributes, the benefits generated through governance (and therefore reliance on complex governance) must go down. ${ }^{8}$ While the intuition for Proposition $l$ is simple, the striking aspect of this result is that, under the matching logic, the ex post crowding out and complementarity effects are logically unnecessary for predicting that ex ante trust leads to lower levels of governance complexity. Conversely, one cannot infer the existence of a crowding out or complementarity effect simply because there is a negative relationship between ex ante trust and governance complexity.

\section{Proposition 2: Under the matching ap- proach, a direct crowding out effect is necessary to generate a positive rela- tionship between the level of ex ante trust and governance complexity.}

The intuition for this result may be expressed as follows. In the matching model, in the presence of a direct crowding out effect, an increase in governance complexity has two opposing effects. First, the benefits generated through governance complexity increase. Second, the benefits generated through trust decline (because of the negative effect of governance complexity on ex post trust). When the direct crowding out effect is strong, the second effect may dominate the first. In such instances, if ex ante trust goes up (which positively affects ex post trust and increases the immediate benefits generated through trust), governance complexity must change for the total level of benefits to remain constant. Given strong direct crowding out, governance complexity must increase to offset the consequences of higher ex ante trust. The surprising implication is that one needs to argue for a negative impact of governance complexity

\footnotetext{
${ }^{8}$ An alternative intuition is to treat (l) as describing a series of isoquants that generate the same levels of benefits, $B$, for different combinations of $t$ and $C$. Regardless of their concavity or convexity, on any isoquant, an increase in $t$ must be offset by a decrease in $C$, since the goal is to select the isoquant that generates the requisite level of $B(=H)$ at the lowest level of $C$ possible.
} 
on ex post trust in order to justify a positive relationship between optimal governance complexity and ex ante trust.

Note that in line with Proposition 2, in the absence of a direct crowding out effect, a complementarity effect alone cannot generate a positive relationship between governance complexity and ex ante trust. On the contrary, in the absence of a direct crowding out effect, complementarity is consistent with a negative relationship between governance complexity and ex ante trust. The intuition is similar to Proposition 1 , since a rise in ex ante trust and, thus, in the benefits generated through trust necessitates a lower level of benefits generated through governance. A lower level of governance complexity suffices (and complementarity only increases the benefits from governance complexity).

Finally, we note that in the matching model neither changes in the cost of governance nor changes in the indirect crowding out effect (for any given direct crowding out effect) play a role in determining the relationship between ex ante trust and optimal governance complexity (see the Appendix). Thus, if scholars have in mind a matching model such as ours, they must be aware that it is unnecessary to invoke either crowding out or complementarity to argue for a negative relationship between ex ante trust and governance complexity. Furthermore, a complementarity effect (of any magnitude) is insufficient to generate a positive relationship between ex ante trust and governance complexity. Rather, a direct crowding out effect is necessary. Alternately, if scholars use a matching approach to generate predictions that are inconsistent with the ones presented here, they should make clear how their assumptions differ from ours.

Next we turn to the maximizing approach.

Proposition 3: Under the maximizing approach, there is no relationship between the level of ex ante trust and governance complexity if there are neither crowding out nor complementority effects.

Put differently, either complementarity or crowding out is necessary for there to be any relationship between governance complexity and ex ante trust. The intuition for this result can be expressed as follows. In the maximizing approach the optimal level of governance com- plexity equates the marginal benefits with the marginal costs. As can be seen from (1), ex ante levels of trust influence the marginal benefits of governance through complementarity between trust and governance (the $\gamma f \mathrm{~g}$ term), as well as through the crowding out effect built into the contribution of trust in the benefit function $(g)$. Without complementarity, the $\gamma f \mathrm{~g}$ term does not exist, and without crowding out (3), ex ante trust will simply increase the level of trust in the relationship independent of governance complexity. Ex ante levels of trust therefore will play no role in shaping the marginal benefits or costs of governance in the absence of both complementarities and constraints.

Proposition 3 points to important differences for the role of the ex post effects-complementarity and crowding out-in the matching and the maximizing models. In the former, complementarity and crowding out effects are not necessary to produce the result that ex ante trust lowers optimal governance complexity. In the maximizing model, in contrast, at least one of the ex post effects is necessary to generate any relationship between ex ante trust and governance complexity.
Proposition 4: Under the maximizing approach, a strong indirect crowding out effect relative to the direct crowd- ing out effect is necessary to generate a negative relationship between the level of ex ante trust and governance complexity.

The corollary is that if the direct crowding out effect is stronger relative to the indirect crowding out effect, there is a positive relationship between governance complexity and ex ante trust. Thus, as with the matching model, with a direct crowding out effect alone, the relationship between ex ante trust and governance complexity is positive.

The intuition for Proposition 4 is as follows. Ex ante trust affects the marginal benefit of governance complexity in two ways: through the complementarity effect (the $\gamma f g$ term) and through the crowding out effect built into the contribution of trust to the benefit function (g) both via the level of ex post trust. Assume there is no complementarity effect to begin with and consider only the direct crowding out effect. An increase in ex ante trust raises the level of ex post trust. For higher levels of ex post trust, the 
crowding out effect of governance complexity weakens in terms of lowering the marginal effect of ex post trust because the trust benefit function ( $g$ ) is concave. Thus, the marginal benefits of governance complexity increase as ex ante trust goes up. The optimal level of governance complexity is the point where the marginal benefits and costs are identical. This therefore results in a positive relationship between ex ante trust and governance complexity.

Now consider the indirect crowding out effect, which, by definition, strengthens the direct crowding out effect of governance complexity on ex post trust when ex ante trust increases. With an indirect crowding out effect, an increase in ex ante trust has two opposing effects. First, because $g$ is concave, the marginal benefit of governance complexity goes up (as explained above). Second, the strength of the direct crowding out effect increases. This decreases the marginal benefit of governance complexity. If the second effect is stronger than the first (i.e., if the direct crowding out effect is stronger relative to the indirect crowding out effect), ex ante trust will be negatively related to governance complexity.

Proposition 5: Under the maximizing approach, in the absence of a crowding out effect, a complementarity effect is necessary to generate a positive relationship between the level of ex ante trust and governance complexity.

Ex ante levels of trust influence the marginal benefits of governance through complementarity (the $\gamma f g$ term), as well as through the crowding out effect built into the benefits of trust (g) - both via the level of ex post trust. Without crowding out, ex ante trust will simply increase the level of trust in the relationship and therefore strengthen the complementarity effect as well, resulting in a positive relationship between ex ante trust and optimal governance levels. Thus, in the maximizing model complementarity and the direct crowding out effect both "push in the same direction"-toward a positive trustgovernance complexity relationship.

Again, the differences between the matching and maximizing approaches are striking. A strong indirect crowding out effect is necessary to obtain a negative relationship between ex ante trust and governance complexity in the maximizing model; in the matching model such an effect is irrelevant for the direction of the relationship. In the absence of a crowding out effect, a complementarity effect is insufficient to generate $a$ positive relationship between ex ante trust and optimal governance complexity in the matching approach, but it is necessary in the maximizing approach. These results suggest that to the extent that scholars have in mind a maximization model whose structure conforms to ours, they must be aware that it is impossible to specify a relationship between trust and governance complexity absent complementarity, crowding out, or both. Further, on indirect crowding out effect is necessary to argue for a negative trust-governance relationship.

To illustrate the consequences of the complementarity and crowding out effects in both the matching and maximizing approaches, we generate graphs in Figure 3 using a specific set of functional forms that conform to the conditions set out in (1), (2), and (3) (see the Appendix for details). This illustration tellingly shows how with the same basic relationships (i.e., model specification) completely opposite predictions can be generated by simply changing a single assumption about the presence or absence of complementarity and crowding out or about the underlying decision model.

\section{EXTENSIONS AND ALTERNATIVE FORMULATIONS}

While the model we have analyzed has a fairly general form, we recognize nonetheless that not all scholars may choose to model some of the effects in the same way. Accordingly, in this section we explore the consequences of relaxing and changing some of the assumptions underlying our core model. All proofs can be found in the Appendix.

\section{Extension 1: Constant/Increasing Marginal Returns to Ex Post Trust}

In our basic model we assume decreasing marginal returns to trust-that the benefits of trust to exchange increase with the level of trust but at a decreasing rate $\left(\partial^{2} g / \partial T^{2}<0\right)$. While this assumption seems a plausible description of the effects of trust, it is, in fact, unnecessary in the matching approach, which only requires that the benefits of trust increase with the level of trust.

For the maximizing approach, the impact of the direct crowding out effect is sensitive to the 
FIGURE 3

The Effect of Complementarity and Direct and Indirect Crowding Out on the Relationship Between Ex Ante Trust $(t)$ and the Level of Governance Complexity $(C)^{\alpha}$

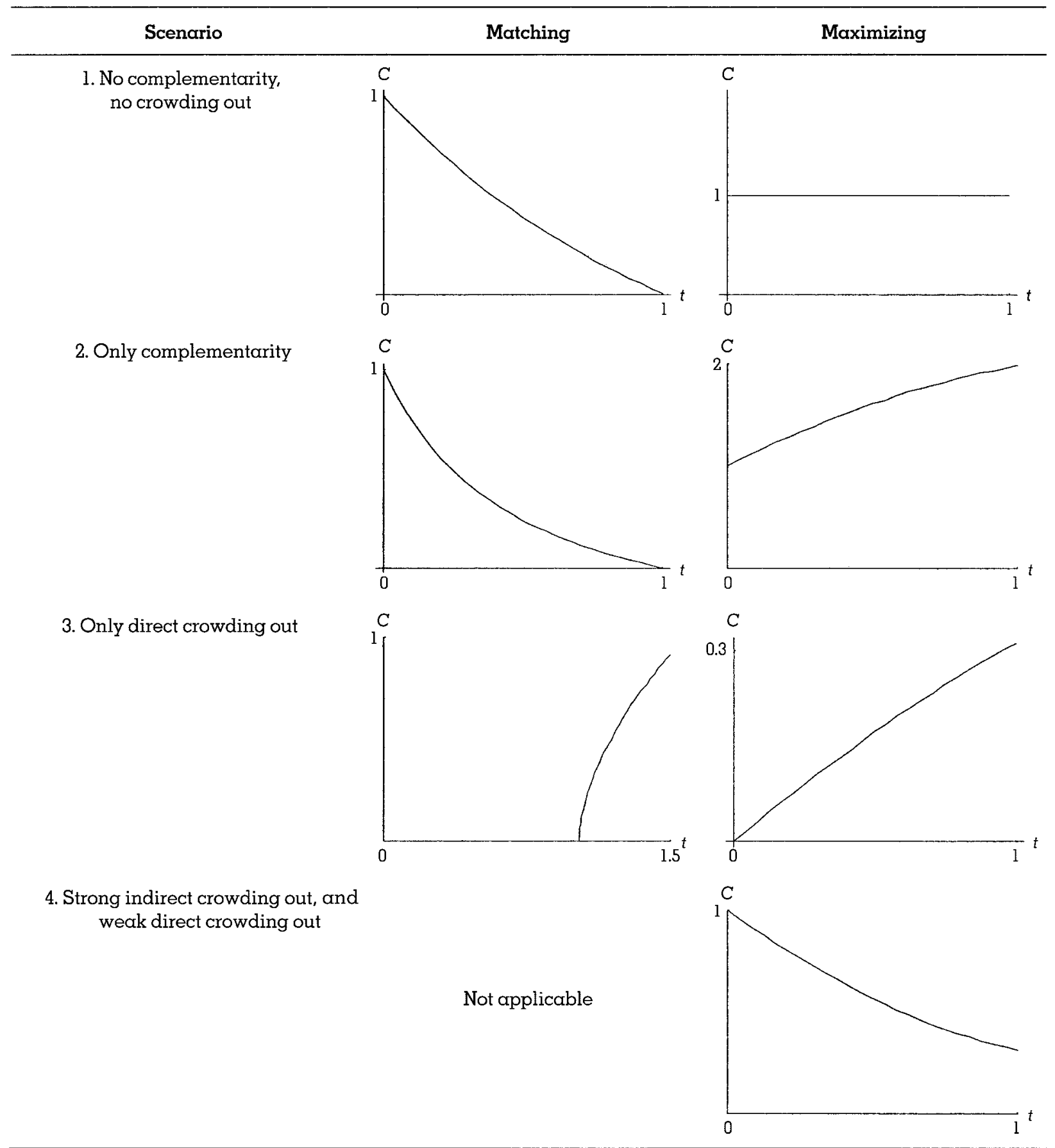

${ }^{a}$ See the Appendix for functional forms used and parameter values.

assumption about returns to trust. With constant returns to trust $\left(\partial^{2} g / \partial T^{2}=0\right)$ or increasing returns to trust $\left(\partial^{2} g / \partial T^{2}>0\right)$, the direct crowding out effect no longer serves as a force that creates a positive association between trust and governance complexity. Recall that this positive asso- 
ciation arose because with the direct crowding out effect an increase in governance complexity lowered the level of ex post trust, but increased its marginal impact owing to the concavity of $g$. Therefore, the conditions laid out in Propositions 4 and 5 become less stringent since the indirect and direct crowding out effects are not pitted against each other anymore. Thus, with constant returns to trust, only the existence of an indirect crowding out effect is necessary to generate a negative relationship between ex ante trust and optimal governance complexity; with increasing returns to trust, only a direct crowding out effect is necessary to generate a negative association between trust and governance complexity (Proposition 4). Note that the presence of an indirect crowding out effect implies the existence of a direct one. With either constant or increasing returns to trust, a complementarity effect is necessary to get a positive association between ex ante trust and governance complexity, whether or not a crowding out effect is present (Proposition 5).

\section{Extension 2: Trust and Governance Ass Substitutes}

In our model we allow for complementarity in the relationship between trust and governance. Now we explore the possibility of a substitution relationship between trust and governancethat is, trust lowers the marginal benefits of governance complexity, and vice versa. Note that this is different from (and may coexist with) the crowding out effect, which is a lowering of the level of trust in a relationship due to the use of complex formal governance mechanisms. In our framework a substitution effect is easily modeled by setting $\gamma<0$, which implies that $f$ and $g$ are substitutes, because each lowers the marginal value of the other (Siggelkow, 2002).

With such a substitution effect, in the matching model we find that a crowding out effect is no longer necessary to generate a positive relationship between ex ante trust and governance complexity (as stated in Proposition 2); it can arise from the substitution effect alone as well. Ex ante trust serves simply to lower the marginal effect of governance complexity, leading to the need for "more" complexity in order to satisfy $B=H$.

In the maximizing model we find that an indirect crowding out effect is no longer necessary to generate a negative association between ex ante trust and governance complexity (as stated in Proposition 4); it can arise from the substitution effect alone. In this model the optimal level of governance complexity equates the marginal benefits of governance complexity to its costs. An increase in ex ante trust lowers the marginal benefits of governance complexity (via the substitution effect) and therefore results in a lower optimal level of governance complexity. Thus, with a substitution effect, at least one of the crowding out effects is now necessary for a positive relationship between ex ante trust and governance complexity (see the Appendix for further details).

\section{Extension 3: Allowing Ex Ante Trust to Affect the Cost of Governance}

In our basic model we only consider the benefits of trust, not its implications for governance costs. It is possible to conceptualize trust not only as acting to mitigate the effects of opportunism and enable adaptation (as in our model) but as acting to lower the marginal cost of governance complexity as well. In other words, ex ante trust could make the setting up of governance itself less costly, for any level of governance complexity. We can modify the model to allow for the existing level of trust to lower the marginal cost of governance complexity $\left(h_{\mathrm{C}, \mathrm{t}}^{\prime \prime}<0\right)$.

As before, the results in the matching model are unaffected, since the costs of governance do not feature in that model directly. In the maximizing model Propositions 3 and 5 are modified. In the absence of both complementarity and crowding out effects, there will now be a positive association between ex ante trust and governance complexity (Proposition 3) so that the complementarity effect is not necessary to generate such on association in the maximizing model (Proposition 5). This is not very surprising, because allowing ex ante trust to lower the marginal cost of governance complexity is analytically equivalent to an additional complementarity effect between ex ante trust and governance complexity: trust enhances the marginal effect of governance complexity on exchange performance.

In the preceding analysis of alternative formulations, we were careful to note how our propositions stated in the previous section change, in order to make transparent the as- 
sumptions on which our results depended. However, the analysis here confirms the robustness of our fundamental point-that the choice of the underlying optimization model (matching or maximizing) matters greatly. An obvious illustration of this point is that the changes we introduce in the model with each extension above have different (and often opposite) implications for the matching and maximizing models. Further, the analysis also shows how our model structure is flexible enough to serve as a platform to explore alternative formulations of the relationships between trust and governance. For instance, crowding in effects-such that governance complexity might encourage the formation of trust (Grundei, 2006) - can also be easily accommodated in our model.

\section{DISCUSSION}

The relationships between trust and formal governance are both fascinating and convoluted. While an increasing number of scholars are asking whether trust and governance are complements or substitutes (Corts \& Singh, 2004; Gulati \& Nickerson, in press; Lazzarini et al., 2004; Luo, 2002; Poppo \& Zenger, 2002; Ryall \& Sampson, in press; Woolthuis et al., 2005), the possible relationships between them are richer than this dichotomization. Besides making the case that we have learned as much as we can from empirical studies that simply ask if trust and governance are complements or substitutes, our analysis takes three important steps toward enhancing our understanding of the relationships between trust and governance.

First, we point to different basic types of relationships between trust and governance, which may, however, coexist: trust may enhance the effect of governance on exchange performance (complementarity), governance may reduce the level of trust between exchange partners (through direct or indirect crowding out), and ex ante trust may influence the choice of governance complexity. Our analysis focuses on showing how the endogenous relationship between ex ante trust and governance is affected by the two exogenous and ex post relationships - the crowding out and the complementarity effects. In our extensions we also considered the possibility of substitution between trust and governance complexity, as well as the impact of trust on the cost of governance. The dichotomous complements-substitutes characterization masks this variety of possible relationships and can only lead to terminological confusion. We therefore hope that our work encourages scholars to clearly specify the underlying mechanisms they invoke when proposing particular relationships between trust and governance complexity.

Second, we also draw attention to the need for clarity about the logic underlying the optimization problem that decision makers implicitly face when making governance choices. As we show, the maximizing and the matching models lead to very different predictions about the relationships between ex ante trust and governance complexity. This difference fundamentally arises from the fact that, in the matching approach, the decision maker equates the level of benefits generated through trust and governance to the perceived need for such benefits in the form of safeguards and adaptation implied by transaction characteristics; in the maximizing model the decision maker equates the marginal benefits and marginal costs of governance complexity. Given the diversity of reported empirical results on the nature of the relationship between ex ante trust and governance complexity, we hope we have persuaded scholars that articulating the nature of the underlying decision-making model-matching or maximizing -is critical for any meaningful aggregation of results, and even debate among scholars. Further setting aside the empirical question of which of the two models has better explanatory power, there may also be fruitful opportunities for assessing their relative behavioral plausibility, perhaps in laboratory settings.

Third, our analysis helps us to formally state and prove which effects are necessary (or unnecessary) to generate positive and negative relationships between ex ante trust and governance complexity. To obtain a negative trustgovernance relationship, neither crowding out nor complementarity is necessary in the matching model, whereas a strong indirect crowding out effect relative to the direct crowding out effect is necessary in the maximizing model. In fact, in the maximizing model either a complementarity or crowding out effect is necessary for any trust-governance relationship. To obtain a positive trust-governance relationship, a direct crowding out effect is necessary in the matching model, and a complementarity or direct crowding out ef- 
fect is necessary in the maximizing model. As can be seen, these conditions vary significantly across the matching and maximizing models, and (at least to us) were not obvious prior to our anclysis. We hope these results will be helpful to scholars both in strengthening the rationale for their arguments about the expected relationships between trust and governance complexity and in interpreting their empirical findings appropriately. Of course, as is always the case with a formal theorizing exercise, it is certainly possible to formulate other models with different assumptions, which will also lead to different results. However, we believe that our analysis serves the valuable purpose of sensitizing scholars to the need for explicitly altering the structure of the model in order to reach different conclusions.

As evidence of the flexibility of our model structure for exploring such variations, we have ourselves analyzed some extensions to our basic model, such as allowing for constant/increasing returns to trust, assuming a substitution effect between trust and governance, and allowing trust to lower governance costs. While some of the results alter as a consequence, others remain unchanged, and the overall pattern of results continues to show a shorp difference between the matching and maximizing approaches. In addition to this analytical flexibility, our model structure also lends itself to some interpretive flexibility. For instance, while our results are based on the assumption of (conditionally) optimal decision making informed by knowledge of the complementarity and crowding out effects, they also can be used to compare the choices of a decision maker who is "blind" to certain effects with the optimal choices (e.g., in the matching model the choices of a decision maker who ignores the direct crowding out effect will show a negative association between trust and governance, whereas it should be a positive one).

Our model also lends itself to exploration into how trust and governance may coevolve over time. In additional simulations (not reported here), we took the resulting levels of ex post trust in the relationship in period $n$ as the ex ante level of trust in period $n+1$, to see how trust and governance complexity change over time. ${ }^{9} \mathrm{We}$ found two basic patterns. First, in situations

\footnotetext{
${ }^{9}$ Note that the decision maker still optimizes only during each period rather than across multiple periods.
}

with a positive association between ex ante trust and governance complexity (e.g., only direct crowding out in matching or maximizing), trust and governance complexity move in the same direction over time. Note that this does not imply that both will increase; they could also decline together. Second, when a negative relationship is present between ex onte trust and governance complexity (e.g., only complementarity in matching or strong indirect crowding out in maximizing), trust and governance complexity move in opposite directions over time. Again, in such situations trust could increase or decrease, as long as governance complexity moves in the opposite direction. Finally, the relationship between ex ante trust and governance complexity may itself change over time as a result of changes in trust levels (which influence the magnitude of the crowding out effects when present). We hope that the possibility of doing this kind of analysis encourages other scholars to explore these ideas further.

In addition to clarifying theorizing about trust and governance, our results can help with interpreting empirical findings, as well as with specifying better empirical tests. For instance, some scholars might argue that a crowding out effect is implausible in the real world, while others may question the basis for complementarity. Our model is useful to both, demonstrating what the results would be in the absence of each effect individually. Thus, by arguing for the existence or absence of effects such as crowding out and complementarity, one can make rigorously derived, competing predictions about the expected sign of the relationship between trust and governance complexity. ${ }^{10}$

However, an additional interesting direction for research might be to move concepts such as crowding out and complementarity out of the category of unobserved mechanisms, to explicit moderators that change the sign of the relationship between trust and governance. Thus, instead of simply looking for relationships between trust and governance complexity, scholars could also attempt to exploit sources of variation in the magnitudes of the complementarity

\footnotetext{
${ }^{10}$ Our results are about the association between ex ante trust and governance complexity. Because the relationship between ex ante trust and ex post trust is always positive, the sign of the relationship between ex post trust and governance complexity is the same as that of the one we studied.
} 
and crowding out effects. Such an approach could go a long way toward reconciling apparently disparate prior results-if the differences could be shown to arise from differences in the crowding out and complementarity effects across the samples of different studies. In order to encourage progress in this direction, in Table 1 we present an attempt to map the effects studied in our model to possible empirical indicators. We focus on the three key parameters of interest in our model: the direct and indirect crowding out effects and the complementarity effect.

We have argued that governance mechanisms may crowd out trust because the reliance on governance may be seen as a signal of distrust. Thus, we would expect the crowding out effect to be stronger when the perceived signal is stronger, and the signal of distrust may be stronger if it is common practice to not use any governance mechanism. For example, certain markets rely on handshakes rather than written agreements to close deals. Insisting on a contract in such instances will rapidly crowd out trust. We have also argued that an indirect crowding out effect could arise when trust development is hampered because of the attribution of trustworthy behavior to the contract. Such misattribution may be less likely when the partners to the exchange share a sophisticated understanding of the strengths and limits of formal governance (e.g., in the form of legal expertise).

Trust may complement governance mechanisms when it is impossible to specify all contingencies ex ante. Thus, we expect the complementarity effect to be stronger in situations of uncertainty and volatility. Furthermore, trust complements agreements in the sense that clauses that are nonenforceable in courts are upheld within the relationship. In part, such agreements may provide necessary coordination mechanisms that enhance exchange performance (Mayer \& Argyres, 2004). This latter effect should be stronger when the need for coordination between exchange partners is high-for example, in situations of high interdependence between them (Gulati et al., 2005; Thompson, 1967).

We also recognize the limitations to our research. As with all attempts at formal analysis, we trade off analytical rigor against realism rather explicitly. We assume (conditionally) optimizing behavior by a decision maker who is fully informed about the values of the various parameters in the model. Also, in the tradition of transaction cost economics (Williamson, 1975, 1985), as well as research inspired by it that (implicitly or explicitly) treats parties' governance preferences as similar (e.g., Crocker \& Reynolds, 1993), we focus on the decisions of one party; we could view the results from the model as (1) describing the behavior of a disinterested designer who takes the preferences of both parties into account or (2) what would be most preferred by each individual partner-with what actually prevails in any given relationship being also affected by bargaining power (Grossman \& Hart, 1986).

We also focus explicitly on trust transformation during the exchange and take ex ante trust levels as given. As a direct consequence of this choice, we are not concerned in this paper with assurance effects arising from the potential value of future interactions, which may have results similar to those of trust. Our analysis, despite its incorporation of ex post effects into ex ante optimization, is still somewhat static in

TABLE 1

Crowding Out and Complementarity

Effect Is Stronger When...

Direct crowding out

Formal contracts are not common practice-The act of proposing a contract can be perceived as a signal of distrust when trusting individuals propose contracts. The perceived signal strength of distrust should be greater the less common the use of a contract is.

Indirect crowding out

Parties to the exchange lack legal expertise-In such situations, the growth of trust in the relationship may be hampered because of misattributions about cooperative behavior as having arisen from governance rather than from trustworthy behavior.

Complementarity

Ambiguity surrounding exchange is higher-Trust leverages the value of contracts if they are incompletely specified because of ambiguity. If ambiguity is higher, then the complementarity effect should be stronger. 
the sense that we do not model the development of trust over time in the relationship. However, our analysis should still yield directionally correct results since the formulation of the static crowding out effect we have modeled would still be appropriate even if trust in the relationship increased not only with ex ante trust but also with the duration of the relationship. Yet an explicitly dynamic formulation of this trust generation process would doubtless have advantages in terms of tracing the time paths of trust development.

In the interest of analytical tractability, we have modeled governance complexity as a continuous variable. This maps most closely onto formal governance through contracts, which can be of greater or lesser levels of complexity and detail. However, we believe our results are also relevant to the case of discrete governance modes-such as the choice among market, hybrid, and hierarchy-for two reasons. First, the discreteness of these modes may well be primarily a matter of categorization. As many scholars have noted, hierarchical elements are found in markets, market elements in hierarchies, and both in hybrids (Bradach \& Eccles, 1989). Thus, while contracts exist between independent firms of various levels of detail and ownership links exist between firms of various levels of equity (Kale \& Puranam, 2004), this is not inconsistent with a useful definition of ideal types such as markets, hybrids, and hierarchies.

Second, in practice, most studies that predict the choice between discrete governance modes rest on underlying mechanisms that are continuous. For example, increases in transaction hazards require increases in governance safeguards. This leads to predictions about the likelihood of a discrete choice through a latent variable (e.g., in probit or logit models). Our continuous variable, governance complexity, can be thought of as such a latent variable. For these reasons, we believe that our results on governance complexity as a continuous variable should be broadly applicable to the choice of discrete governance modes of increasing levels of complexity.

Despite these limitations, we believe that this paper makes progress toward untangling the complex web of relationships linking trust and governance. Our goal has been to use the simplest and most general formulation possible to make the basic point at the focus of this paper-that the "simple" dichotomization of the relationships between trust and governance into "com- plements" and "substitutes" obscures and confuses more than it simplifies and clarifies.

\section{APPENDIX}

\section{Model Structure}

$B=f(C)+g(T(C, t))+\gamma f(C) g(T(C, t))$ and $\quad(\alpha)$

$K=h(C)$,

where

$C, t \geq 0 ; f(C) \geq 0, f_{C}^{\prime}>0 ;$

$$
\begin{aligned}
& g(T(C, t)) \geq 0, g_{T}^{\prime}>0, g_{T}^{\prime \prime}<0, \\
& T(C, t) \geq 0, T_{t}^{\prime}>0, \text { and } \\
& h(C) \geq 0 ; h_{C}^{\prime}>0 .
\end{aligned}
$$

Complementarity: $\gamma>0$.

Direct crowding out: $T_{C}^{\prime}<0$.

Indirect crowding out: $T_{C, t}^{\prime \prime}<0$.

\section{The Matching Approach}

Let $C^{\star}$ be such that $F_{1} \equiv B-H=0$ at $C^{\star}$. (c) Because for any exogenous variable $\psi \frac{\partial C^{\star}}{\partial \psi}=-\frac{F_{1 \psi}^{\prime}}{F_{1 C}^{\prime}}$ (implicit function theorem),

$$
\begin{gathered}
\frac{\partial C^{*}}{\partial t}=-\frac{F_{1 t}^{\prime}}{F_{1 C}^{\prime}}=-\frac{g_{T}^{\prime} T_{t}^{\prime}+\gamma f g_{T}^{\prime} T_{t}^{\prime}}{f_{C}^{\prime}+g_{T}^{\prime} T_{C}^{\prime}+\gamma f_{C}^{\prime} g+\gamma f g_{T}^{\prime} T_{C}^{\prime}}= \\
-\frac{g_{T}^{\prime} T_{t}^{\prime}(1+\gamma f)}{f_{C}^{\prime}(1+\gamma g)+g_{T}^{\prime} T_{C}^{\prime}(1+\gamma f)} .
\end{gathered}
$$

Proposition 1:

$\gamma=T_{C}^{\prime}=0 \Rightarrow \frac{\partial C^{\star}}{\partial t}=-\frac{g_{T}^{\prime} T_{t}^{\prime}}{f_{C}^{\prime}}$, from $(d)$.

$\therefore \frac{\partial C^{\star}}{\partial t}<0$, from $(1,2)$.

In the absence of complementarity and crowding out effects, there is a negative relationship between ex ante trust and governance complexity. Therefore, neither effect is necessary to generate this negative relationship.

\footnotetext{
${ }^{11}$ Note that we suppress the arguments of functions in the notation to ease readability, but they are taken into account in the analysis.
} 
Proposition 2:

$-g_{T}^{\prime} T_{t}^{\prime}(1+\gamma f)<0$, from $(1,2)$.

$\frac{\partial C^{\star}}{\partial t}>0 \Leftrightarrow f_{C}^{\prime}(1+\gamma g)+g_{T}^{\prime} T_{C}^{\prime}(1+\gamma f)$

$<0$, from $(d)$.

$f_{C}^{\prime}(1+\gamma g)+g_{T}^{\prime} T_{C}^{\prime}(1+\gamma f)<0 \Rightarrow T_{C}^{\prime}<0$, since all other terms are nonnegative, from $(1,2)$.

In order to obtain a positive relationship between ex ante trust and governance complexity, a direct crowding out effect is necessary.

\section{The Maximizing Approach}

$P \equiv B-K=f(C)+g(T(C, t))+$ $\gamma f(C) g(T(C, t))-h(C)$.

$C^{*}$ is such that $\left.P_{C}^{\prime}\right|_{C^{*}}=0$, and if this is a maximum, $P_{C}^{\prime \prime}<0$.

$P_{C}^{\prime}=f_{C}^{\prime}+g_{T}^{\prime} T_{C}^{\prime}(1+\gamma f)+\gamma f_{C}^{\prime} g-h_{C}^{\prime}$.

$F_{2} \equiv P_{C}^{\prime}=f_{C}^{\prime}+g_{T}^{\prime} T_{C}^{\prime}(1+\gamma f)+$

$\gamma f_{C}^{\prime} g-h_{C}^{\prime}=0$.

From the implicit function theorem, $\frac{\partial C^{\star}}{\partial t}=-\frac{F_{2 t}^{\prime}}{F_{2 C}^{\prime}}$.

From (f), at the maximum $F_{2 C}^{\prime}<0$ so that the sign of $\frac{\partial C^{*}}{\partial t}$ will be the same as the sign of $F_{2 t}^{\prime}$.

$F_{2 t}^{\prime}=\left(g_{T}^{\prime \prime} T_{t}^{\prime} T_{C}^{\prime}+g_{T}^{\prime} T_{C, t}^{\prime \prime}\right)(1+\gamma f)+\gamma f_{C}^{\prime} g_{T}^{\prime} T_{t}^{\prime}$.

Proposition 3:

$T_{C}^{\prime}=T_{C, t}^{\prime \prime}=\gamma=0 \Rightarrow F_{2 t}^{\prime}=0$.

$\therefore \frac{\partial C^{\star}}{\partial t}=0$, from (i).

In the absence of crowding out and complementarity effects, there is no relotionship between ex ante trust and governance complexity. At least one of these effects is therefore necessary to obtain any trust-governance relationship.

Proposition 4:

$\frac{\partial C^{\star}}{\partial t}<0 \Leftrightarrow F_{2 t}^{\prime}<0$.

$F_{2 t}^{\prime}<0 \Rightarrow g_{T}^{\prime \prime \prime} T_{t}^{\prime \prime} T_{C}^{\prime}<\left|g_{T}^{\prime} T_{C, t}^{\prime \prime}\right|$, from $(1,2, j)$.

$\therefore F_{2 t}^{\prime}<0 \Rightarrow \frac{\left|T_{C, t}^{\prime \prime}\right|}{\left|T_{C}^{\prime}\right|}>\frac{\left|g_{T}^{\prime \prime} T_{t}^{\prime}\right|}{g_{T}^{\prime}}$.

A strong indirect crowding out effect, $T_{C, t}^{\prime \prime}$ relative to the direct crowding out effect, $T_{C}^{\prime}$, in which "strong" is precisely defined as $\frac{\left|T_{C, t}^{\prime \prime}\right|}{\left|T_{C}^{\prime}\right|}>\frac{\left|g_{T}^{\prime \prime} T_{t}^{\prime}\right|}{g_{T}^{\prime}}$, is necessary to generate a negative relationship between the extent of governance complexity and the level of ex ante trust.

Proposition 5:

$T_{C}^{\prime}=T_{C, t}^{\prime \prime}=0 \Rightarrow F_{2 t}^{\prime}=\gamma f_{C}^{\prime} g_{T}^{\prime} T_{t}^{\prime}$.

$\therefore \frac{\partial C^{\star}}{\partial t}>0 \Leftrightarrow \gamma>0$, since all other terms are positive, from $(1,2, j)$.

In the absence of crowding out effects, a complementarity effect is necessary (and any magnitude of complementarity effect is sufficient) for a positive relationship between ex ante trust and governance complexity.

\section{Specific Functional Form for Grophic Analysis}

We illustrate our results in Figure 3 with a functional form that satisfies our assumptions:

$$
\begin{gathered}
f(C)=C, g(T)=T-\frac{T^{2}}{6}, h(C)=\frac{C^{2}}{2} \text { and } \\
T(C, t)=\frac{3 t}{2}-\frac{t^{2}}{4}-\omega C-\phi C t .
\end{gathered}
$$

For matching, we set $H=1$. We consider different scenarios in which we manipulate complementarities $(\gamma)$ or direct $(\omega)$ or indirect $(\phi)$ crowding out effects. We use the following parameter values for Figure 3:

\begin{tabular}{lcc}
\hline Scenario & Matching & Maximizing \\
\hline 1. No complementarity, & $\gamma=0, \omega=0$, & $\gamma=0, \omega=0$, \\
no crowding out & $\phi=0$ & $\phi=0$ \\
2. Only & $\gamma=1, \omega=0$, & $\gamma=1, \omega=0$, \\
complementarity & $\phi=0$ & $\phi=0$ \\
3. Only direct & $\gamma=0, \omega=1.75$, & $\gamma=0, \omega=1$, \\
crowding out & $\phi=0$ & $\phi=0$ \\
4. Strong indirect & Not applicable & $\gamma=0, \omega=0$, \\
crowding out and & & $\phi=1$ \\
weak direct & & \\
crowding out & & \\
\hline
\end{tabular}

\section{Extensions and Boundary Conditions}

§1: Constant/increasing marginal returns to ex post trust $\left(g_{T}^{\prime \prime} \geq 0\right)$ 
In the matching approach,

$\frac{\partial C^{\star}}{\partial t}$ does not depend on $g_{T}^{\prime \prime}$ (see $\left.[d]\right)$.

In the maximizing approach,

$g_{T}^{\prime \prime}=0 \Rightarrow F_{2 t}^{\prime}=\left(g_{T}^{\prime} T_{C, t}^{\prime \prime}\right)(1+\gamma f)+\gamma f_{C}^{\prime} g_{T}^{\prime} T_{t}^{\prime}$ from $(j)$.

$\left(g_{T}^{\prime} T_{C, t}^{\prime \prime}\right)(1+\gamma f)+\gamma f_{C}^{\prime} g_{T}^{\prime} T_{t}^{\prime}<0 \Rightarrow T_{C, t}^{\prime \prime}<0$, from $(1,2)$.

$\therefore T_{C, t}^{\prime \prime}<0$ is necessary for $\frac{\partial C^{\star}}{\partial t}<0$, since all other terms are nonnegative, from $(1,2)$.

$g_{T}^{\prime \prime}>0 \Rightarrow F_{2 t}^{\prime}=\left(g_{T}^{\prime \prime} T_{t}^{\prime \prime} T_{C}^{\prime}+g_{T}^{\prime} T_{C, t}^{\prime \prime}\right)(1+\gamma f)+\gamma f_{C}^{\prime} g_{T}^{\prime} T_{t}^{\prime}$ from (j), and $g_{T}^{\prime \prime} T_{t}^{\prime \prime} T_{C}^{\prime}<0, g_{T}^{\prime} T_{C, t}^{\prime \prime}<0$, from $(1,2)$.

$\left(g_{T}^{\prime \prime} T_{t}^{\prime \prime} T_{C}^{\prime}+g_{T}^{\prime} T_{C, t}^{\prime \prime}\right)(1+\gamma f)+\gamma f_{C}^{\prime} g_{T}^{\prime} T_{t}^{\prime}<0 \Rightarrow T_{C}^{\prime}<0$.

$\therefore$ A strong indirect crowding out effect relative to the direct crowding out effect (Proposition 4) is no longer necessary for $\frac{\partial C^{\star}}{\partial t}<0$; however, at least a direct crowding out effect is necessary for $\frac{\partial C^{*}}{\partial t}<0$ (because an indirect crowding out effect implies a direct one).

If $g_{T}^{\prime \prime}=0, F_{2 t}^{\prime}>0 \Rightarrow \gamma>0$.

If $g_{T}^{\prime \prime}>0, F_{2 t}^{\prime}>0 \Rightarrow \gamma>0$.

$\therefore$ If $g_{T}^{\prime \prime} \geq 0, \gamma>0$ is necessary for $\frac{\partial C^{\star}}{\partial t}>0$, whether crowding out is present or absent (compare with Proposition 5).

\$2: Trust and governance as substitutes $(\gamma<0)$

In the matching approach,

$T_{C}^{\prime}=T_{C, t}^{\prime \prime}=0 \Rightarrow \frac{\partial C^{\star}}{\partial t}=-\frac{g_{T}^{\prime} T_{t}^{\prime}(1+\gamma f)}{f_{C}^{\prime}(1+\gamma g)}$, from (d).

$\frac{\partial C^{\star}}{\partial t}>0 \Leftrightarrow(1+\gamma g)$ and $(1+\gamma f)$ have opposite signs, from $(1,2)$.

$(1+\gamma f)<0<(1+\gamma g) \Leftrightarrow-\frac{1}{g}<\gamma<-\frac{1}{f}$ or

$(1+\gamma g)<0<(1+\gamma f) \Leftrightarrow-\frac{1}{f}<\gamma<-\frac{1}{g}$.

Hence, even in the absence of crowding out, it is possible to generate a positive relationship between ex ante trust and governance complexity-that is, crowding out is no longer necessary for a positive trust-governance relationship (compare Proposition 2).
In the maximizing approach,

$T_{C}^{\prime}=T_{C, t}^{\prime \prime}=0 \Rightarrow F_{2 t}^{\prime}=\gamma f_{C}^{\prime} g_{T}^{\prime} T_{t}^{\prime}$.

$\therefore \frac{\partial C^{\star}}{\partial t}<0 \Leftrightarrow \gamma<0$, since all other terms are positive, from $(1,2)$.

Thus, with substitution, indirect crowding out is no longer necessary to generate a negative relationship between ex ante trust and governance complexity (compare Proposition 4).

$\frac{\partial C^{\star}}{\partial t}>0 \Leftrightarrow F_{2 t}^{\prime}>0$.

$F_{2 t}^{\prime}>0 \Rightarrow\left(g_{T}^{\prime \prime} T_{t}^{\prime \prime} T_{C}^{\prime}+g_{T}^{\prime} T_{C, t}^{\prime \prime}\right)(1+\gamma f)>0$, since all other terms are negative, from $(1,2)$.

If $(1+\gamma f)>0, \frac{\partial C^{*}}{\partial t}>0 \Rightarrow g_{T}^{\prime \prime} T_{t}^{\prime} T_{C}^{\prime}>\left|g_{T}^{\prime} T_{C, t}^{\prime \prime}\right|$,

from $(1,2)$.

$\therefore \frac{\partial C^{\star}}{\partial t}>0 \Rightarrow \frac{\left|T_{C, t}^{\prime \prime}\right|}{\left|T_{C}^{\prime}\right|}<\frac{\left|g_{T}^{\prime \prime} T_{t}^{\prime}\right|}{g_{T}^{\prime}}$.

If $(1+\gamma f)<0, \frac{\partial C^{\star}}{\partial t}>0 \Rightarrow g_{T}^{\prime \prime} T_{t}^{\prime} T_{C}^{\prime}<\left|g_{T}^{\prime} T_{t, C}^{\prime \prime}\right|$, from

$(1,2)$.

$\therefore \frac{\partial C^{\star}}{\partial t}>0 \Rightarrow \frac{\left|T_{C, t}^{\prime \prime}\right|}{\left|T_{C}^{\prime}\right|}>\frac{\left|g_{T}^{\prime \prime} T_{t}^{\prime}\right|}{g_{T}^{\prime}}$.

$(1+\gamma f)=0 \Rightarrow \frac{\partial C^{\star}}{\partial t}<0$.

Thus, a strong direct crowding out effect (relative to the indirect effect) is necessary to obtain $\frac{\partial C^{\star}}{\partial t}>0$ if $(1+\gamma f)>0$. A strong indirect crowding out effect (relative to the direct effect) is necessary to obtain $\frac{\partial C^{\star}}{\partial t}>0$ if $(1+\gamma f)<0$ (compare Proposition 5). If $(1+\gamma f)=0$, then $\frac{\partial C^{*}}{\partial t}<0$.

§3: Allowing ex ante trust to affect cost of governance $\left(h_{C, t}^{\prime \prime}<0\right)$

In the matching approach, the cost of governance does not feature in the expression for $\frac{\partial C^{\star}}{\partial t}$ (see [d]). Therefore, Propositions 1 and 2 remain unaffected if ex ante trust reduces the cost of governance for any level of complexity.

In the maximizing approach, instead of $K=h(C)$ (b), we let $K=h(C, t)$

and $h(C, t) \geq 0 ; h_{C}^{\prime}>0 ; h_{C, t}^{\prime \prime}<0$. 
$P \equiv B-K=f(C)+g(T(C, t))+\gamma f(C) g(T(C, t))$

$-h(C, t)$.

First- and second-order conditions (w.r.t. C) remain the same; see (f) and (g).

Let $F_{3} \equiv P_{C}^{\prime}=f_{C}^{\prime}+g_{T}^{\prime} T_{C}^{\prime}(1+\gamma f)+\gamma f_{C}^{\prime} g$ $-h_{C}^{\prime}=0$.

From the implicit function theorem, $\frac{\partial C^{\star}}{\partial t}=-\frac{F_{3 t}^{\prime}}{F_{3 C}^{\prime}}$.

If this is a maximum, $F_{3 C}^{\prime}<0$ so that the sign of $\frac{\partial C^{\star}}{\partial t}$ will be the same as the sign of $F_{3 t}^{\prime}$.

$F_{3 t}^{\prime}=\left(g_{T}^{\prime \prime} T_{t}^{\prime \prime} T_{C}^{\prime}+g_{T}^{\prime} T_{C, t}^{\prime \prime}\right)(1+\gamma f)+\gamma f_{C}^{\prime} g_{T}^{\prime} T_{t}^{\prime}$

$-h_{C, t}^{\prime \prime}$.

$T_{C}^{\prime \prime}=T_{C, t}^{\prime \prime}=\gamma=0 \Rightarrow F_{3 t}^{\prime}=-h_{C, t}^{\prime \prime}>0$, from $\left(j^{\prime}\right)$.

$\therefore \frac{\partial C^{\star}}{\partial t}>0$.

Thus, in the absence of complementarity and (in)direct crowding out effects, $\frac{\partial C^{\star}}{\partial t}>0$. That is, neither complementarity nor crowding out is necessary for $\frac{\partial C^{\star}}{\partial t}>0$ (which modifies both Propositions 3 and 5). Proposition 4 remains unchanged.

\section{REFERENCES}

Anderson, E., \& Weitz, B. 1989. Determinants of continuity in conventional industrial channel dyads. Marketing Science, 8: 310-323.

Arrow, K. J. 1974. The limits of organization. New York: Norton.

Banerjee, A. V., \& Duflo, E. 2000. Reputation effects and the limits of contracting: A study of the Indian software industry. Quarterly Journal of Economics, 115: 989-1017.

Batenburg, R. S., Raub, W., \& Snijders, C. 2003. Contacts and contracts: Dyadic embeddedness and the contractual behavior of firms. Research in the Sociology of Organizations: The Governance of Relations in Markets and Organizations, 20: 135-188.

Bhattacharya, R., Devinney, T. M., \& Pillutla, M. M. 1998. A formal model of trust based on outcomes. Academy of Management Review, 23: 459-472.

Bradach, J. L., \& Eccles, R. G. 1989. Price, authority, and trust-From ideal types to plural forms. Annual Review of Sociology, 15: 97-118.

Buskens, V., \& Raub, W. 2002. Embedded trust: Control and learning. Advances in Group Processes, 19: 167-202.

Camerer, C. 2003. Behavioral game theory. Princeton, NJ: Russell Sage Foundation.

Camerer, C., \& Knez, M. 1996. Coordination, organizational boundaries and fads in business practices. Industrial and Corporate Change, 5: 89-112.

Coase, R. H. 1937. The nature of the firm. Economica, 4: 386-405.
Corts, K. S., \& Singh, J. 2004. The effect of repeated interaction on contract choice: Evidence from offshore drilling. Journal of Law, Economics \& Organization, 20: 230-260.

Cremer, J. 1993. Corporate culture and shared knowledge. Industrial and Corporate Change. 2: 351-386.

Crocker, K. J., \& Reynolds, K. J. 1993. The efficiency of incomplete contracts: An empirical analysis of Air Force engine procurement. RAND Journal of Economics, 24: 126-146.

Cyert, R. M., \& March, J. G. 1963. A behavioral theory of the firm. Malden, MA: Blackwell.

Das, T. K., \& Teng, B.-S. 1998. Between trust and control: Developing confidence in partner cooperation in alliances. Academy of Management Review, 23: 491-512.

Deutsch, M. 1973. The resolution of conflict. New Haven, CT: Yale University Press.

Enzle, M. E., \& Anderson, S. C. 1993. Surveillant intentions and intrinsic motivation. Journal of Personality and Social Psychology, 64: 257-266.

Frey, B. S. 1997. A constitution for knaves crowds out civic virtues. Economic Journal, 107: 1043-1053.

Ghoshal, S., \& Moran, P. 1996. Bad for practice: A critique of the transaction cost theory. Academy of Management Review, 21: 13-47.

Granovetter, M. 1985. Economic action and social structure: The problem of embeddedness. American Journal of Sociology, 91: 481-510.

Grossman, S. J., \& Hart, O. D. 1986. The costs and benefits of ownership: A theory of vertical and lateral integration. Journal of Political Economy, 94: 691-719.

Grundei, J. 2006. Examining the relationship between trust and control in organizational design: (How) can divergent requirements be reconciled? In R. M. Burton, B. Eriksen, D. D. Håkonsson, \& C. C. Snow (Eds.), Organization design: The evolving state-of-the-art: 43-65. Boston: Springer.

Gulati, R. 1995. Does familiarity breed trust? The implications of repeated ties for contractual choice in alliances. Academy of Management Journal, 38: 85-112.

Gulati, R., Lawrence, P. R., \& Puranam, P. 2005. Adaptation in vertical relationships: Beyond incentive conflict. Strategic Management Journal, 26: 415-440.

Gulati, R., \& Nickerson, J. A. In press. Interorganizational trust, governance choice, and exchange performance. Organization Science.

Gulati, R., \& Sytch, M. 2008. Does familiarity breed trust? Revisiting the antecedents of trust. Managerial and Decision Economics, 29: 165-190.

Hayek, F. A. 1945. The use of knowledge in society. American Economic Review, 35: 519-530.

Kale, P., \& Puranam, P. 2004. Choosing equity stakes in technology-sourcing relationships: An integrative framework. California Management Review, 46(3): 77-99.

Kalnins, A., \& Mayer, K. J. 2004. Relationships and hybrid contracts: An analysis of contract choice in information technology. Journal of Law, Economics \& Organization, 20: 207-229.

Klein, B., Crowwford, R. G., \& Alchion, A. A. 1978. Vertical inte- 
gration, appropriable rents, and the competitive contracting process. Journal of Law and Economics, 21: 297-326.

Klein, B., \& Leffler, K. B. 1981. The role of market forces in assuring contractual performance. Journal of Political Economy, 89: 615-641.

Kramer, R. M. 1999. Trust and distrust in organizations: Emerging perspectives, enduring questions. Annual Review of Psychology, 50: 569-598.

Lazzarini, S. G., Miller, G. J., \& Zenger, T. R. 2004. Order with some law: Complementarity versus substitution of formal and informal arrangements. Journal of Law, Economics \& Organization, 20: 261-298.

Levin, J. 2003. Relational incentive contracts. American Economic Review, 93: 835-857.

Lindskold, S. 1978. Trust development, the GRIT proposal, and the effects of conciliatory acts on conflict and cooperation. Psychological Bulletin, 88: 772-793.

Luo, Y. 2002. Contract, cooperation, and performance in international joint ventures. Strategic Management Journal, 23: 903-919.

Macaulay, S. 1963. Non-contractual relations in business: A preliminary study. American Sociological Review, 28: 55-67.

Macneil, I. R. 1978. Contracts: Adjustment of long-term economic relations under classical, neoclassical and relational contract law. Northwestern University Law Review, 72: 854-905.

Malhotra, D., \& Murnighan, J. K. 2002. The effects of contracts on interpersonal trust. Administrative Science Quarterly, 47: 534-559.

March, J., \& Simon, H. 1958. Organizations. New York: Wiley.

Mayer, K. J., \& Argyres, N. S. 2004. Learning to contract: Evidence from the personal computer industry. Organization Science, 15: 394-410.

Mayer, R. C., Davis, J. H., \& Schoorman, F. D. 1995. An integrative model of organizational trust. Academy of Management Review, 20: 709-734.

Mellewigt, T., Madhok, A., \& Webel, A. 2007. Trust and formal contracts in interorganizational relationships-Substitutes and complements. Managerial and Decision Economics, 28: 833-847.

Milgrom, P., \& Roberts, J. 1995. Complementarities and fit strategy, structure, and organizational change in manufacturing. Journal of Accounting and Economics, 19(23): $179-208$.

Parkhe, A. 1993. Strategic alliance structuring: A game theoretic and transaction cost examination of interfirm. Academy of Management Journal, 36: 794-829.

Petersen, T. 1992. Individual, collective, and systems ratio- nality in work groups: Dilemmas and market-type solutions. American Journal of Sociology, 98: 469-510.

Poppo, L., \& Zenger, T. 2002. Do formal contracts and relational governance function as substitutes or complements? Strategic Management Journal, 23: 707-725.

Rempel, J. K., Holmes, J. G., \& Zanna, M. P. 1985. Trust in close relationships. Journal of Personality and Social Psychology, 49: 95-112.

Ring, P. S., \& Van de Ven, A. H. 1992. Structuring cooperative relationships between organizations. Strategic Management Journal, 13: 483-498.

Ryall, M. D., \& Sampson, R. C. In press. Formal contracts in the presence of relational enforcement mechanisms: Evidence from technology development projects. Management Science.

Saussier, S. 2000. Transaction costs and contractual incompleteness: The case of Electricite de France. Journal of Economic Behavior \& Organization, 42: 189-206.

Siggelkow, N. 2002. Misperceiving interactions among complements and substitutes: Organizational consequences. Management Science, 48: 900-916.

Strickland, L. H. 1958. Surveillance and trust. Journal of Personality, 26: 200-215.

Thompson, J. D. 1967. Organizations in action. New York: McGraw-Hill.

Uzzi, B. 1997. Social structure and competition in interfirm networks: The paradox of embeddedness. Administrative Science Quarterly, 42: 37-69.

Vanneste, B. S., \& Puranam, P. In press. Repeated interactions and contractual detail: Identifying the learning effect. Organization Science.

Williamson, O. E. 1975. Markets and hierarchies-Analysis and antitrust implications. New York: Free Press.

Williamson, O. E. 1985. The economic institutions of capitalism. New York: Free Press.

Williamson, O. E. 1991. Comparative economic organization: The analysis of discrete structural alternatives. Administrative Science Quarterly, 36: 269-296.

Williamson, O. E. 1993. Calculativeness, trust, and economic organization. Journal of Law and Economics, 36: 453-486.

Williamson, O. E. 1996. The mechanisms of governance. New York: Oxford University Press.

Woolthuis, R. K., Hillebrand, B., \& Nooteboom, B. 2005. Trust contract and relationship development. Organization Studies, 26: 813-841.

Zaheer, A., \& Venkatraman, N. 1995. Relational governance as an interorganizational strategy: An empirical test of the role of trust in economic exchange. Strategic Management Journal, 16: 373-392.

Phanish Puranam (ppuranam@london.edu) is an associate professor of strategic and international management at London Business School. He received his Ph.D. in management from the Wharton School at the University of Pennsylvania. His research focuses on interorganizational coordination both between firms (alliances, outsourcing arrangements) and within firms (acquisitions, interdivisional collaboration).

Bart S. Vanneste (bvanneste.phd2004@london.edu) is a Ph.D. candidate in strategic and international management at London Business School. His research focuses on the governance and social structure of exchange relationships. 